\title{
EFFICIENT METHODS FOR ARSENIC REMOVAL FROM GROUNDWATER
}

\author{
G. BADALIANS GHOLIKANDI ${ }^{1}$, H.R. ORUMIEH ${ }^{2} \&$ R. RIAHI ${ }^{3}$ \\ ${ }^{1}$ Power and Water University of Technology (PWUT), Water Research Institute (WRI), Tehran, Iran. \\ ${ }^{2}$ Pars Arianab Consulting Engineers, Esfahan, Iran. \\ ${ }^{3}$ Water Research Institute (WRI), Water and Wastewater Research Center (WWRC), Tehran, Iran.
}

\begin{abstract}
Arsenic may be found in water that has flowed through arsenic-rich rocks. Arsenic is a toxic, trace element that is ubiquitous in nature. It can easily be transported from the sediment to the surrounding pore-water. Severe health effects have been observed in populations drinking arsenic-rich water over long periods in countries worldwide. A 2007 study found that over 137 million people in more than 70 countries are probably affected by arsenic poisoning of drinking water. In groundwater, arsenic combines with oxygen to form inorganic pentavalent arsenate and trivalent arsenite. Most arsenic treatments fall into four process categories: ion exchange, membrane process, adsorption, or chemical precipitation. This study investigates the potential of removing arsenic from groundwater by using two process categories - activated alumina and lime softening. Arsenic adsorption by commercially available activated alumina is surveyed and its efficiency investigated. We have incorporated some of the valuable literature on arsenic remediation by adsorption. According to results of three activated alumina pilot studies, considering influence of adsorption time, temperature, $\mathrm{pH}$, alumina quantity, arsenic concentration, and different alumina production resources, it has high efficiency for arsenic removal. Adsorption isotherm for both species of arsenic (III and V) is compatible with both Freundlich and Langmuir models (correlation coefficient $>0.93$ ). The prevalent $\mathrm{pH}$ range for arsenate was between 6 and 8. Modified activated alumina can remove arsenate at the influent $\mathrm{pH}$ of $8.1 \pm 0.4$ to below the maximum concentration level (MCL). The exhausted media passed the Toxicity Characteristic Leaching Procedure (TCLP) test with respect to arsenic. Lime softening operated within the optimum $\mathrm{pH}$ range of more than 10.5 is likely to provide a high percentage of arsenic removal (90\%) for influent concentrations of up to $0.05 \mathrm{mg} / \mathrm{L}$. It may be difficult to reduce consistently to $0.01 \mathrm{mg} / \mathrm{L}$ by lime softening alone. Systems using lime softening may require secondary treatment to meet that goal.
\end{abstract}

Keywords: activated alumina, arsenic contamination, groundwater, removal efficiency, softening.

\section{INTRODUCTION}

Groundwater is a remarkable source for supplying drinking water as well as in sustainable irrigated crop production in Iran [1]. Extent and severity of arsenic contamination of groundwater is a crucial issue and a threat to human health and food safety. Alarming information has emerged in recent decades about the widespread presence of arsenic (As) in groundwater used to supply drinking water in many countries on all continents (Fig. 1) [9]. A 2007 study found that over 137 million people in more than 70 countries are probably affected by arsenic poisoning of drinking water. Hundreds of millions of people, mostly in developing countries, daily use drinking water with arsenic concentrations several times higher than the World Health Organization (WHO) recommendation of $0.01 \mathrm{mg} / \mathrm{L}$ of water [3, 4]. Dangerous arsenic concentrations in natural waters are now a worldwide problem and often referred to as a 20th-21st century calamity. High arsenic concentrations have been reported recently from the USA, China, Chile, Bangladesh, Taiwan, Mexico, Argentina, Poland, Canada, Hungary, Japan, and India [5]. In 2001, US-EPA published a new $0.01 \mathrm{mg} / \mathrm{L}$ standard for arsenic in drinking water [6].

Arsenic is a crystal-shape metalloid which is brittle in nature and grayish white in color. Arsenic rarely occurs in a free state and is found largely in combination with sulfur, oxygen, 


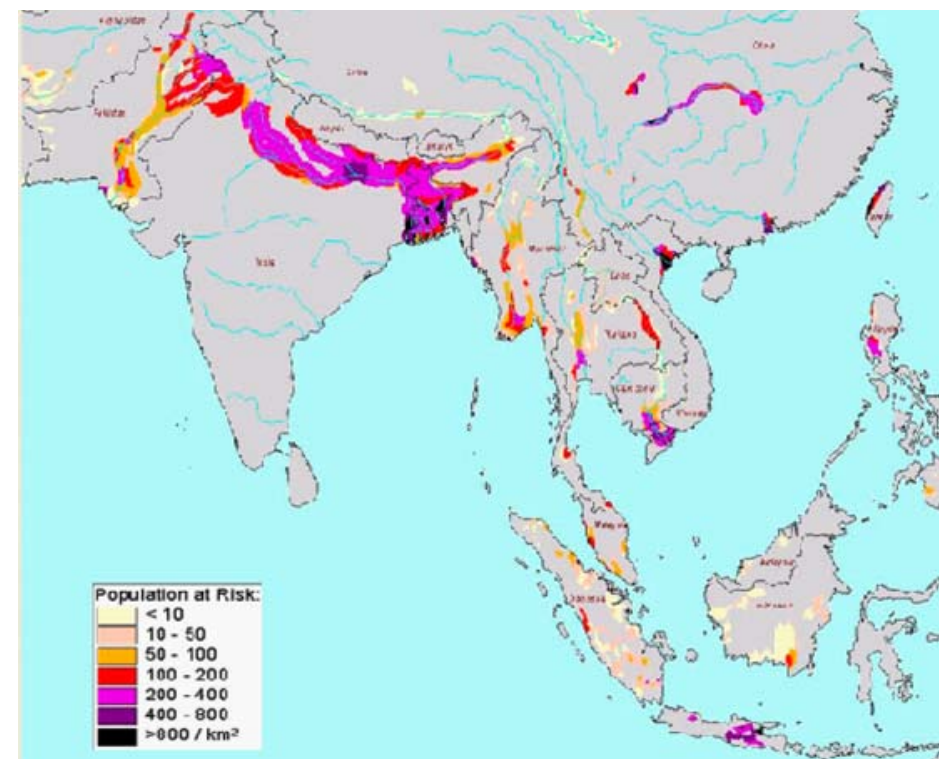

Figure 1: Population at arsenic contaminated groundwater risk [14].

and iron. Unlike other heavy metalloids and oxyanion-forming elements, arsenic can be mobilized under a wide range of oxidizing and reducing conditions at the $\mathrm{pH}$ values typically found in groundwater ( $\mathrm{pH}$ 6.5-8.5). Whereas all other oxyanion-forming elements are found within the $\mu \mathrm{g} / \mathrm{L}$ range, arsenic can be found within the $\mathrm{mg} / \mathrm{L}$ range. Arsenic has four main chemical forms having oxidation states, $-3,0,+3$, and +5 , but in groundwater its predominant forms are inorganic oxyanions of trivalent arsenite (As III) or pentavalent arsenate (AsV) [7]. The toxicity of different arsenic species varies in the order arsenite $>$ arsenate $>$ monomethylar sonate>dimethylarsinate. Trivalent arsenic is about 60 times more toxic than arsenic in the oxidized pentavalent state, and inorganic arsenic compounds are about 100 times more toxic than organic arsenic compounds [8]. The organic forms of arsenic are quantitatively insignificant and are found mostly in surface waters or in areas severely affected by industrial pollution [9]. The relative concentrations of As (III) to As (V) vary widely, depending on the redox conditions in the geological environment [10]. The two most important factors controlling the speciation of arsenic and, to some extent, solubility are $\mathrm{pH}$ and redox potential. Under oxidizing conditions at $\mathrm{pH}$ less than $6.9, \mathrm{H}_{2} \mathrm{AsO}_{4}^{-}$is the dominant species, whereas $\mathrm{HAsO}_{4}^{-2}$ predominates at higher $\mathrm{pH}$. Under reducing conditions at a $\mathrm{pH}$ value less than 9.2, the uncharged arsenite species $\mathrm{H}_{3} \mathrm{AsO}_{3}$ is dominant. In contrast to the $\mathrm{pH}$ dependency of As (V), As (III) was found virtually independent of $\mathrm{pH}$ in the absence of other specifically adsorbed anions. Most often, more trivalent arsenic than pentavalent arsenic is found in reducing groundwater conditions, whereas the converse is true in oxidizing groundwater conditions. Unlike other toxic trace metals whose solubility tends to decrease as $\mathrm{pH}$ increases, most oxyanions, including arsenate, tend to become more soluble as $\mathrm{pH}$ increases. When most other metals become insoluble within the neutral $\mathrm{pH}$ range, arsenic is soluble at even near-neutral $\mathrm{pH}$ in relatively high concentrations. That is why groundwater is easily contaminated with arsenic and other oxyanions $[11,12]$. The severe arsenic intoxication occurs when the element affects the nervous system which may cause coma and, in intoxications 
with 70-80 mg/L, may be even mortal. Digestive system, nervous system, respiratory system, and skin all are highly sensitive to the element and arsenic may cause skin cancer, keratinization, and hyperpigmentation.

If a completely satisfactory, arsenic-free water source cannot be established, the short-term goal should be to reduce arsenic levels in drinking water as much as possible, as quickly as possible, even if regulatory standards cannot be immediately met. It should be recalled that health effects of arsenic are dose-dependent, and a partial solution is better than no solution. The implementation of a temporary solution should not be used as a reason to delay design and implementation of a long-term plan [13]. Most arsenic treatments fall into four process categories: ion exchange, membrane process, adsorption, or chemical precipitation. Ionexchange treatments are very limited in their ability to remove arsenic because of exchange competition from other anions found in groundwater. Membrane processes are very effective at removing arsenic from groundwater, but the cost is high. Accordingly, adsorption and chemical precipitation processes are being explored for low-cost, effective treatments $[6,12]$. Historically, the most common technologies for arsenic removal have been coagulation with metal salts, lime softening, and iron/manganese removal. Coagulation processes are sometimes unable to efficiently remove arsenic to the recommended low levels. As a result, various alternate technologies have been developed or adapted that are capable of removing arsenic to trace levels. One of these advanced treatment options is activated alumina [13]. Present review aimed to study the efficiency of two arsenic removal methods; adsorption using activated alumina and lime softening, to investigate a safe and feasible method for removing arsenic from drinking water in simple household treatment systems especially for the contaminated groundwater resources in West Iran.

\section{MATERIAL AND METHODS}

Two process categories are considered: (1) activated alumina; (2) lime softening. Three pilot studies are investigated:

(a) A field program to evaluate the performance of ALCAN AAFS-50 arsenic removal media [15]. This field trial program was carried out by 2002 to evaluate the performance of this arsenic removal media at Well \# 15, Kirtland Air Force Base, New Mexico. Well \# 15 historically has water with arsenic concentration more than $0.01 \mathrm{mg} / \mathrm{L}$. One of the media tested was ALCAN AAFS-50; a ferric coated activated alumina, with Density-dry $1.12 \mathrm{~g} /$ $\mathrm{cm}^{3}$, BET (Brauner, Emmett, and Teller) surface area $139.8 \mathrm{~cm}^{2} / \mathrm{g}$, size of media $28 \times 48$ mesh, volume of media loaded $5.0 \mathrm{~L}$, and empty bed contact time 5.0 minutes. The scanning electron microscope (SEM) analysis of the virgin AAFS-50 and the exhausted media grains after the completion of the column tests with a JEOL JSM-6300V scanning electron microscope equipped with an energy-dispersive X-ray emission analyzer, and the toxicity characteristic procedure (TCLP) test for exhausted media, according to the EPA-Method 1311 (1992) were also carried out. To ensure that the arsenic in the well water was in the pentavalent form before entering the media columns, the arsenic feed water was treated with $5 \%$ commercial sodium hypochlorite solution to a level of approximately $1 \mathrm{mg} / \mathrm{L}$ of residual chlorine in a holding tank. Source groundwater was obtained downstream from a pump station. This water entered a high-density polyethylene tank via a flow control valve. The water from the feed tank passed through individual flow totalizers before entering the bottom of each individual media column. Each media column was divided into two sections. The bottom contained graded gravel, which served as a containment base for the media and as a uniform water flow distributor. On top of the gravel bed laid the arsenic sorption media bed 
of uniform size composition. The water flowed up through each packed column at the flow rate of approximately $1.0 \mathrm{~L} / \mathrm{min}$ at an empty bed contact time (EBCT) of 5 minutes. At the EBCT of 5 minutes, the bed behaved as a packed column. Both influent and effluent samples $(250 \mathrm{~mL})$ were collected for laboratory analyses on a daily basis. The more common operational control parameters and the water quality parameters were measured on a daily basis. The field setup was operated until breakthrough, defined by an effluent water arsenic concentration of $0.005 \mathrm{mg} / \mathrm{L}$. After breakthrough, each individual column was emptied, and samples of the saturated media were sent for SEM analysis and TCLP test.

(b) Batch experiments carried out by 2004 to evaluate the performance of ALCAN AAFS50 arsenic removal media at some villages in West Iran [16]. The efficiency of modified activated alumina with iron compounds with trade name ALCAN AAFS-50 was studied Equilibrium batch experiments were carried out using shaker incubator and arsenic was analyzed with Silver Diethyl Dithiocarbamate Spectrophotometric (SDDC) method. The media tested was a ferric coated activated alumina, with Density-dry $0.91 \mathrm{~g} / \mathrm{cm}^{3}$, BET surface area $200-250 \mathrm{~cm}^{2} / \mathrm{g}$, and size of media $28 \times 48$ mesh. Effects of initial concentration of arsenic, adsorbent dose, oxidation state of arsenic, reaction time, $\mathrm{pH}$, and oxidation with chlorine on adsorption were studied.

(c) An activated alumina pilot plant operated from 1997 to 1999 to evaluate the performance of Alcoa medium for arsenic removal from drinking water [17]. An activated alumina pilot plant was installed and operated to evaluate the performance of Alcoa medium for arsenic removal from drinking water. Source water was supplied by 700 -ft-deep bedrock well. The capacity of this well was $190-220 \mathrm{~L} / \mathrm{sec}$. The total soluble arsenic concentration was in average $0.062 \mathrm{mg} / \mathrm{L}$. About $30 \%$ of the soluble arsenic existed as As(III) and the rest was As(V). Particulate arsenic was not detected in the raw water. After passing through the cartridge filters, the filtered water splits into the two activated alumina trains (two parallel sets of two tanks in series). Each fiberglass mineral tank $(132.1 \mathrm{~cm}$ tall by $40.6 \mathrm{~cm}$ in diameter) contains about $1.8 \mathrm{~m}^{3}$ of Alcoa DD-2 activated alumina. The depth of the activated alumina bed is about $84 \mathrm{~cm}$. The influent flows downward through the activated alumina bed and the treated water returns to the top of the tank through a 1-inch polyvinyl chloride riser tube. The differential pressure across the medium was about 3 psi. The hydraulic loading rate to each tank is $0.085 \mathrm{~L} / \mathrm{cm}^{2}$.sec and the EBCT is 4.3 minutes. Physical characteristics of Alcoa DD-2 activated alumina $(14 \times 28 \mathrm{mesh})$ are: white granule, surface area $250 \mathrm{~m}^{2} / \mathrm{g}$, total pore volume $0.395 \mathrm{cc} / \mathrm{g}$, total porosity $56.2 \%$, bulk density $620-830 \mathrm{~kg} / \mathrm{m}^{3}$, and abrasion loss $1.6 \mathrm{wt} \%$. Its chemical composition (wt \%) is: $\mathrm{Al}_{2} \mathrm{O}_{3}(92.2), \mathrm{Na}_{2} \mathrm{O}(0.90), \mathrm{Fe}_{2} \mathrm{O}_{3}(0.08), \mathrm{SiO}_{2}(0.09)$, loss on ignition (water, 6.5), Alumina XRD phase amorphors, boehmite, and gamma. The first set of the tanks (TA1 and TA2) were used as roughing filters and the second set (TB1 and TB2) were used as polishing filters. During the preliminary sampling phase of this study, water samples were collected at four locations: (1) at the inlet; (2) after the roughing tank of train 1 (TA1); (3) after the polishing tank of train 1 (TB1); and (4) at the combined effluent of trains 1 and 2. Preliminary sampling consisted of biweekly sample collection and analysis. Biweekly long-term sampling and analysis was performed for 36 weeks (18 events).

The pilot plant operated by 2006 to evaluate the performance of the softening method by lime for arsenic removal from drinking water [18]. The Plant includes following units: (1) chemical pollutant stock tank: this unit comprises of a polyethylene tank with $80 \mathrm{~L}$ volume and $50 \mathrm{~L}$ effective volume, an electric stirrer including an electromotor with $1450 \mathrm{rpm}$, axe and stirring blade, and a dozing pump. The pollutant solutions including arsenic solutions are prepared in this tank and injected to the fixed-level tank; (2) fixed-level tank: a polyethylene tank 
Table 1: Samples' preparation [18].

\begin{tabular}{lccccc}
\hline Pilot stage & $\begin{array}{c}\text { Concerned } \\
\text { content of } \\
\text { arsenic in raw } \\
\text { water }(\mathrm{mg} / \mathrm{L})\end{array}$ & $\begin{array}{c}\text { System rate } \\
(\mathrm{L} / \mathrm{min})\end{array}$ & $\begin{array}{c}\text { Pollutant stock } \\
\text { injected } \\
(\mathrm{mg} / \mathrm{L})\end{array}$ & $\begin{array}{c}\text { Arsenic } \\
\text { concentration } \\
\text { in the injected } \\
\text { pollutant stock } \\
(\mathrm{mg} / \mathrm{L})\end{array}$ & $\begin{array}{c}1000 \mathrm{mg} / \mathrm{L} \\
\text { arsenic added } \\
\text { to pollutant } \\
\text { stock (mg/L) }\end{array}$ \\
\hline A & 0.05 & 3 & 5 & 1.875 & 18.6 \\
B & 0.1 & 3 & 5 & 3.714 & 37.2 \\
C & 0.15 & 3 & 5 & 5.571 & 55.9 \\
D & 0.2 & 3 & 5 & 7.428 & 74.4 \\
\hline
\end{tabular}

with $500 \mathrm{~L}$ volumes equipped with float and electromechanical stirrer with $1450 \mathrm{rpm}$ velocity. The tank is connected to the water supply line from one side and its level remains fixed. The other side of the tank is connected to the dozing pumps, which injects the chemical pollutant solution to the tank, and the electromechanical stirrer makes a homogenous mixture with the raw water; (3) rapid maxing unit: the unit comprises of three parts: rapid mixture tan, stirrer with variable rpm, and stirrer blades. The unit is made of Plexiglas and all the calculations have been done based on Camp's theory presented in 1965. The section of the tank is quadratic with $20 \mathrm{~cm}$ sides and its effective depth is $20 \mathrm{~cm}$ and total depth of the tank is $30 \mathrm{~cm}$. For prevention from formation of eddy current, is baffle on the walls installed; (4) coagulation unit: the tank of the unit is made of polyethylene and has an effective volume of $200 \mathrm{~L}$ An electromotor with zero to $60 \mathrm{rpm}$ and paddle blades is used for stirring the tank; (5) clarification unit: the crosssection of this unit is rectangular, made of Plexiglas, and the duration of current inertia is 4 hours; the effective volume of the pool is $628 \mathrm{~L}$ and its depth is $70 \mathrm{~cm}$. The sludge resulting from sedimentation is moved through the sloped bottom of the pool to the collecting hopper which is located in the center of the pool; (6) chlorine and lime water mixture preparation and injection unit: the mixture was prepared separately in polyethylene tanks in rapid mixture unit (Table 1).

Samples were collected at three locations: (1) after fixed-level tank for raw water; (2) after flocculation tank; and (3) after clarification tank. Table (2) shows the analytical results. In all stages of the test the $\mathrm{pH}$ level and hardness of the raw water were continuously controlled. Considering the importance of coagulation and flocculation process, sampling was considered before and after the unit to determine the process efficiency. To ensure the hardness $(\mathrm{TH}=236 \mathrm{mg} / \mathrm{L}$ as $\left.\mathrm{CaCO}_{3}\right)$, the feed water was treated with $93.64 \mathrm{mg}$ calcium chloride $\left(\mathrm{CaCl}_{2}, 77 \%\right.$ purity). The Plant was operated at four stages (A, B, C, \& D) with initial concentrations of 50, 100, 150, and $200 \mathrm{mg} / \mathrm{L}$ respectively. Different As (V) concentrations in feed water was prepared using arsenic pentoxide $\left(\mathrm{As}_{2} \mathrm{O}_{5}\right)$. The techniques for analyses followed the APHA-Standard Methods [19].

\section{RESULTS AND DISCUSSION}

\subsection{Activated alumina}

For 25 years, activated alumina has been the preferred media for arsenic removal from water. The ALCAN specialty aluminas have developed a new, improved grade ActiGuard AAFS50 
with up to three times the capacity of standard activated alumina [8]. Historically, regeneration was the accepted method of making activated alumina systems cost-effective. Regeneration, however, has some drawbacks, including the handling and storage of chemicals, additional processing steps, and the disposal of regeneration effluent. According to the product information documents, the material is a granule and doesn't break down or deteriorate with use as iron-based media. The low pressure drop provides a system requiring less maintenance. Prefiltered water will allow the adsorptive system to operate virtually without back washing. ALCAN AAFS-50's capacity for As (III) adsorption is about $40 \%$ its capacity for As (V). Oxidation is recommended to assist with As (III) removal, when possible. Simple chlorination will oxidize As (III) to As (V) allowing complete removal [8].

(a) The field trial program was carried out at Well \# 15, Kirtland Air Force Base, New Mexico showed that this media was able to remove arsenate and meet the total arsenic maximum contaminant level (MCL) of $0.01 \mathrm{mg} / \mathrm{L}$ in drinking water [15]. The arsenate removal capacity was defined at a breakthrough effluent concentration of $0.005 \mathrm{mg} / \mathrm{L}$ arsenic. At an influent $\mathrm{pH}$ of $8.1 \pm 0.4$ (Temperature $24-26^{\circ} \mathrm{C}$, average arsenic concentration $0.013 \pm$ $0.0009 \mathrm{mg} / \mathrm{L}$ ), the arsenate removal capacity of AAFS-50 was $33.5 \mathrm{mg}$ As (V)/L of dry media $(0.03 \mathrm{mg} \mathrm{As}(\mathrm{V}) / \mathrm{g}$ of media on a dry basis). Silicate, fluoride, and bicarbonate ions were removed by ALCAN AAFS-50; chloride, nitrate, and sulphate ions were not removed the media. The average conductivity values of the influent and treated water were 421630 and $437647 \mu \mathrm{S} / \mathrm{cm}$, respectively. The turbidity of both the influent and treated water were below detection, indicating that both the influent and treated water were not turbid and well below the turbidity maximum contaminant level of 1 normal turbidity unit (NTU). At operating $\mathrm{pH}$ more than 7.0, the structural integrity of the AAFS-50 media was good, as indicated by the constant flow rate observed for the duration of the test. The exhausted media passed the toxicity characteristic procedure (TCLP) test with respect to arsenic $(0.0001 \mathrm{mg} / \mathrm{L})$ and therefore could be disposed as non-hazardous waste. This study was limited to the adsorption of As (V) because the feed water was pre-chlorinated. Groundwater contaminated with arsenic may contain As (III) species, and therefore, pre-oxidation of As (III) to As (V) is required unless the media performance is evaluated for the removal of As (III). The scanning electron microscope (SEM) analysis of the virgin AAFS-50 and the exhausted media grains after the completion of the column tests did not show any changes in the structural morphology of the media. This indicates that the media integrity was maintained and that the bed characteristics did not change, an observation further substantiated by the stable water flow rate $(1.0 \mathrm{~L} / \mathrm{min}$ ) observed throughout the test (volume of water treated until breakthrough: 12.986 L) (Fig. 2) [13].

(b) Considering contamination of drinking water to arsenic in some villages in West Iran, and according to results of this pilot study, modified activated alumina has high efficiency for removal of arsenic and can reduce arsenic concentration under WHO guidelines [16, 20]. Adsorption isotherm for both species of arsenic (III and V) is compatible with both Freundlich and Langmuir models (correlation coefficient > 0.93). Removal efficiency increases as a result of increasing dose and reaches to $98 \%$ for As (V) during 2 hours. Adsorption is first order reaction and removal rate for concentration of 0.421 and $1.15 \mathrm{mg} / \mathrm{L}$ was $91 \%$ and $66 \%$ respectively. Removal efficiency increases 1.54 times from $61 \%$ to $94 \%$ with increasing of adsorption time from $15 \mathrm{~min}$ to $60 \mathrm{~min}$ for primary concentration of $0.25 \mathrm{mg} / \mathrm{L}$. For As (III) the highest removal was $30 \%$ with adsorbent dose $=2000 \mathrm{mg} / \mathrm{L}$. Our study showed that absorption of arsenic has direct relation with increasing of $\mathrm{pH}$ up to 8 , then decreases with increasing of $\mathrm{pH}$ up to 14 . For arsenate the highest removal was observed at $\mathrm{pH}$ between 6 and 8 and removal efficiency was 

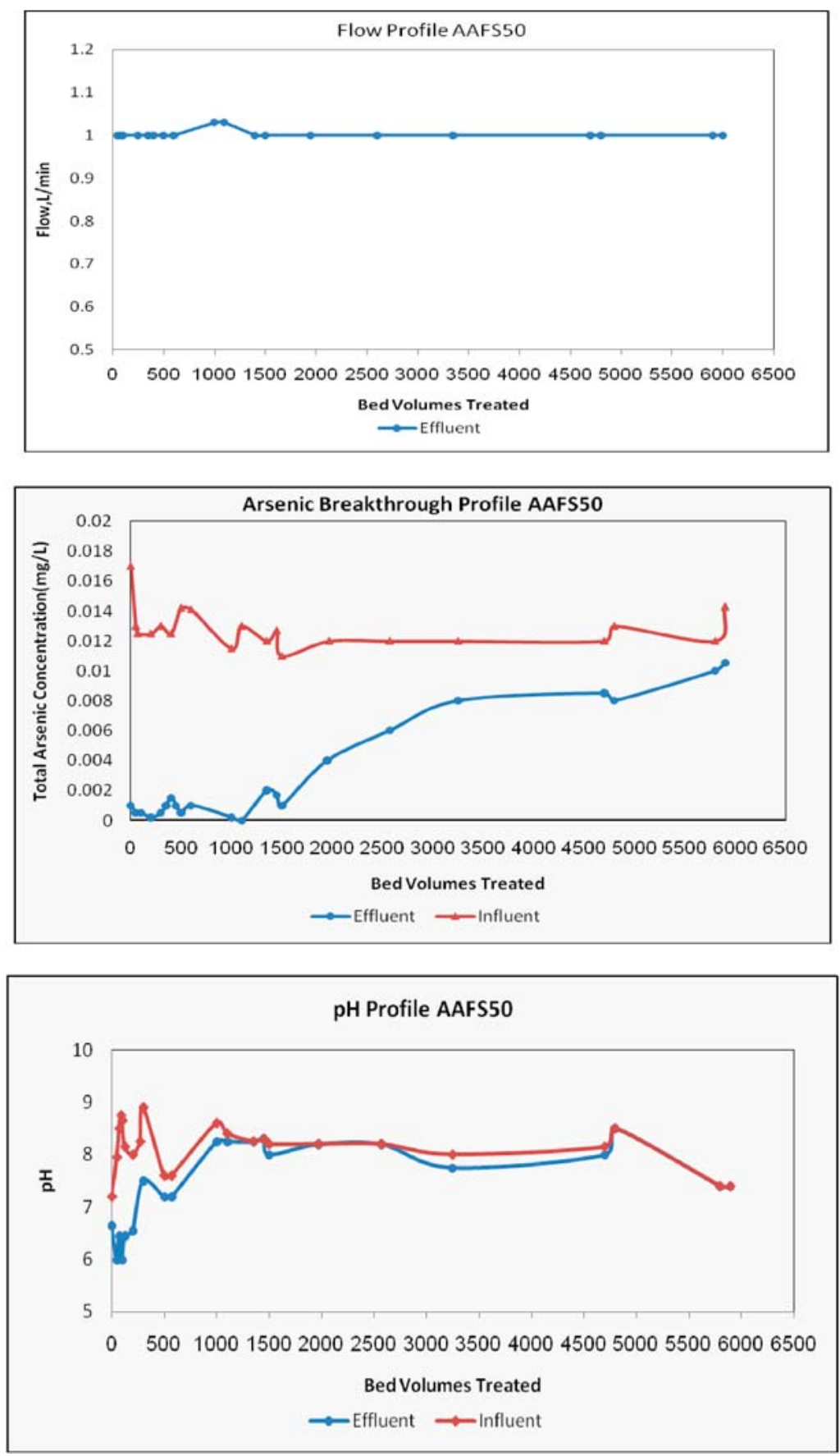

Figure 2: Analytical results [15]. 
higher than $90 \%$. The highest removal for primary concentration of $0.5 \mathrm{mg} / \mathrm{L}$ with adsorbent dose $2000 \mathrm{mg} / \mathrm{L}$, was $95 \%$ at $\mathrm{pH} 8$ that was achieved during 2 hours. Totally for activated alumina used at research $\mathrm{pH}$ can not affect removal efficiency. The prevalent $\mathrm{pH}$ range at monitoring stations was 6 to 8 . Chloride ion could decrease adsorption of activated alumina $2.3 \%$. According to sulfate, the rate was $11 \%$. Oxidation with $4 \mathrm{mg} / \mathrm{L}$ chlorine could convert $99 \%$ of As (III) to As (V) (initial concentration of As $=0.55 \mathrm{mg} / \mathrm{L}$. For chlorine this amount was $61 \%$. Removal of As (III) using chlorine oxidation increased from $19.6 \%$ to $94 \%$ at pH 6. Column study showed that treatment system was able to remove arsenic of water containing $1 \mathrm{mg} / \mathrm{L}$ $\mathrm{As}(\mathrm{V})$ up to $19000 \mathrm{BVs}$ with EBCT $=10 \mathrm{~min}$ that equalled to 133 operation days. With half EBCT (5 min) the treated BVs decreased to 17000 (70 operation days) (Figs. 3 to 9) [3, 16].

(c) An activated alumina pilot plant was installed and operated to evaluate the performance of Alcoa medium for arsenic removal from drinking water [17]. Total arsenic concentration at the inlet ranged from 0.034 to $0.076 \mathrm{mg} / \mathrm{L}$ with an average of $0.054 \mathrm{mg} / \mathrm{L}$. Samples collected after the roughing tank contained total arsenic of 0.014 to $0.051 \mathrm{mg} / \mathrm{L}$ with an average of $0.039 \mathrm{mg} / \mathrm{L}$. Samples collected after the polishing tank contained total arsenic of 0.0004 to $0.027 \mathrm{mg} / \mathrm{L}$ with an average of $0.007 \mathrm{mg} / \mathrm{L}$. The combined treated water (i.e. outlet) had total arsenic concentrations ranging from 0.001 to $0.022 \mathrm{mg} / \mathrm{L}$ with an average of $0.007 \mathrm{mg} / \mathrm{L}$. The average removal percentages were $26.5 \%$ and $87.3 \%$ by the roughing and polishing tanks, respectively. The average overall arsenic removal efficiency was $86.5 \%$ during the long-term sampling. As (III) concentrations averaged $0.008 \mathrm{mg} / \mathrm{L}$ at the inlet, $0.003 \mathrm{mg} / \mathrm{L}$ after the roughing tank, $0.0006 \mathrm{mg} / \mathrm{L}$ after the polishing tank, and $0.0007 \mathrm{mg} / \mathrm{L}$ at the outlet location. Because no oxidative treatments were performed ahead of the activated alumina columns, conversation of As (III) to As (V) was rather unlikely. The removal of As (III) would occur either through a direct sorption of As (III) or via some unexplained conversions of As (III) to As (V) prior to adsorption (Fig. 10). Clifford and Lin [5] had observed some unplanned oxidation of As (III) to As (V) within alumina columns, which resulted in better-than-expected performance for arsenic removal. Nonetheless, the adsorption of As (III) onto activated

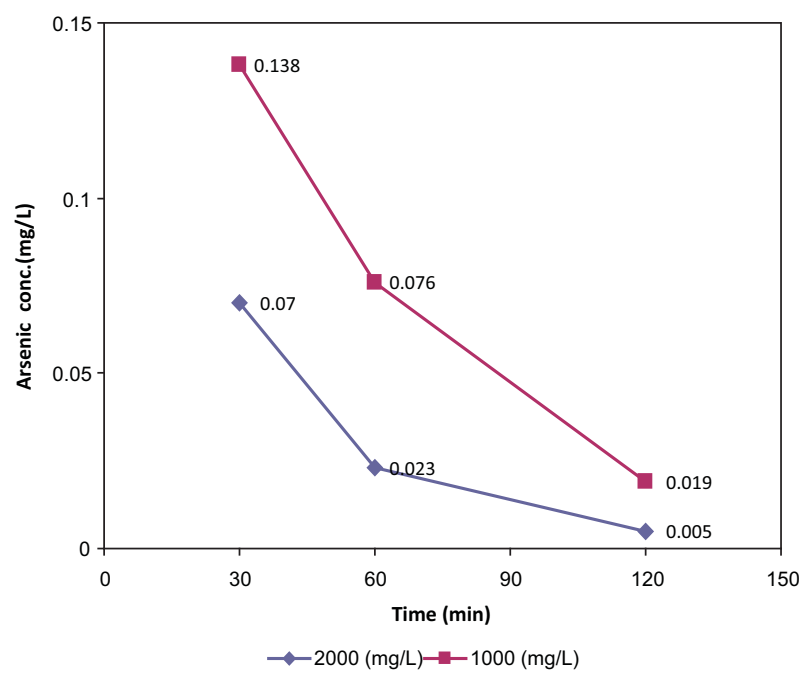

Figure 3: As (V) removal using different quantities of activated alumina, arsenic's initial concentration is $0.25 \mathrm{mg} / \mathrm{L}$ [16]. 

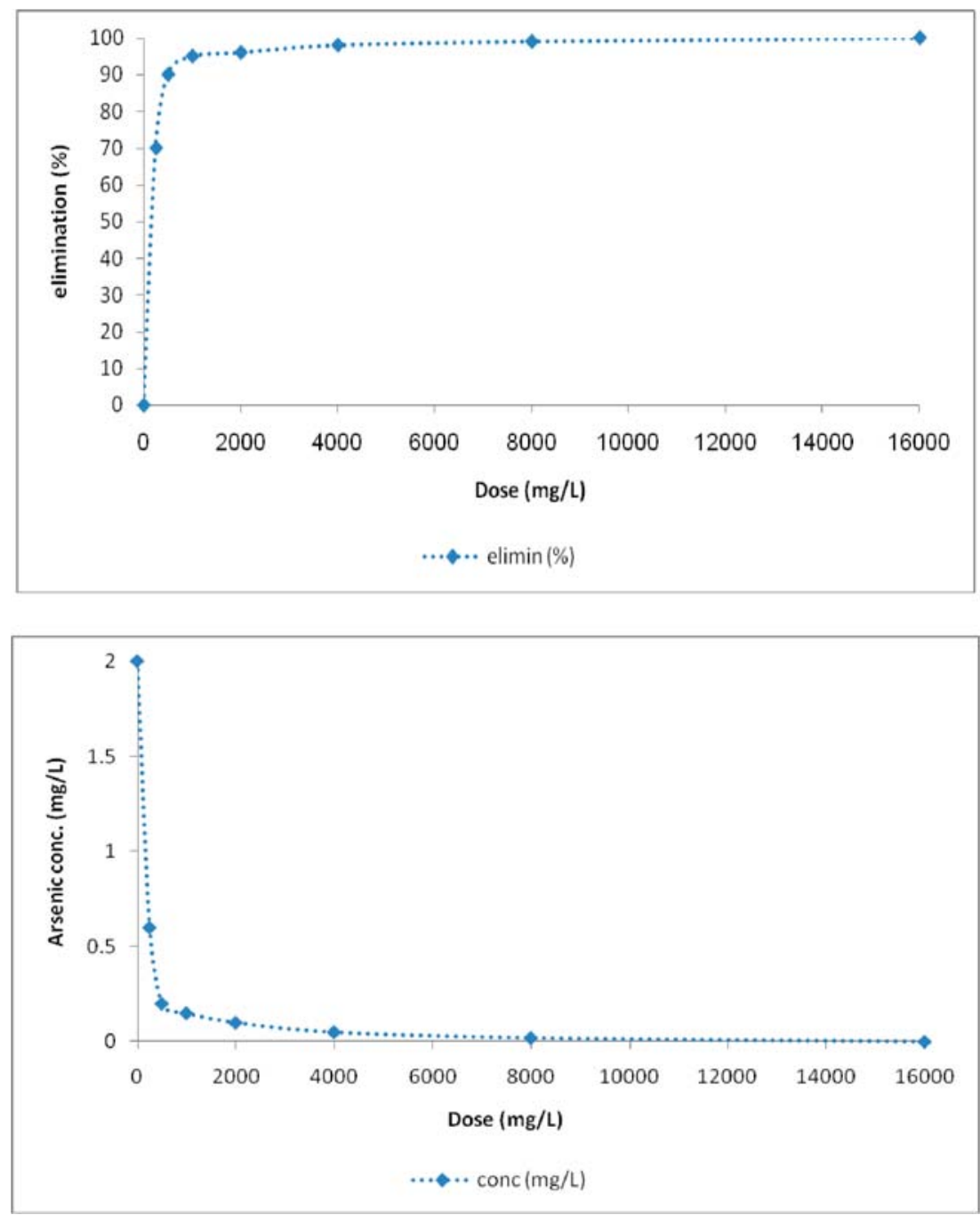

Figure 4: As (V) adsorption using activated alumina; arsenic's initial concentration is $2 \mathrm{mg} / \mathrm{L}$; experience time 24 hours [20].

alumina has been reportedly far less than that of As (V) [22]. Therefore, arsenite should be oxidized to arsenate before activated alumina treatment $[7,8]$.

The average As (V) concentrations were $0.0452 \mathrm{mg} / \mathrm{L}$ at the inlet, $0.0399 \mathrm{mg} / \mathrm{L}$ after the roughing tank, $0.007 \mathrm{mg} / \mathrm{L}$ after the polishing tank, and $0.006 \mathrm{mg} / \mathrm{L}$ at the outlet location. The arsenic in the finished water consists almost entirely of As (V).

The activated alumina capacity of TA1 was nearly exhausted after treating $10.050 \mathrm{BV}$ of water. The arsenic breakthrough occurred in TA2 after treating $9.156 \mathrm{BV}$ of water. The estimated activated alumina capacity was $0.30 \mathrm{~g} / \mathrm{kg}\left(219 \mathrm{~g} / \mathrm{m}^{3}\right)$. This value is comparable to the capacity of $0.26 \mathrm{~g} / \mathrm{kg}$ reported by Fox [24] in his study with a source water of $\mathrm{pH} 8.3$ and containing 0.05 to $0.35 \mathrm{mg} / \mathrm{L}$ As (V). Clifford [23] estimated the practically achievable 

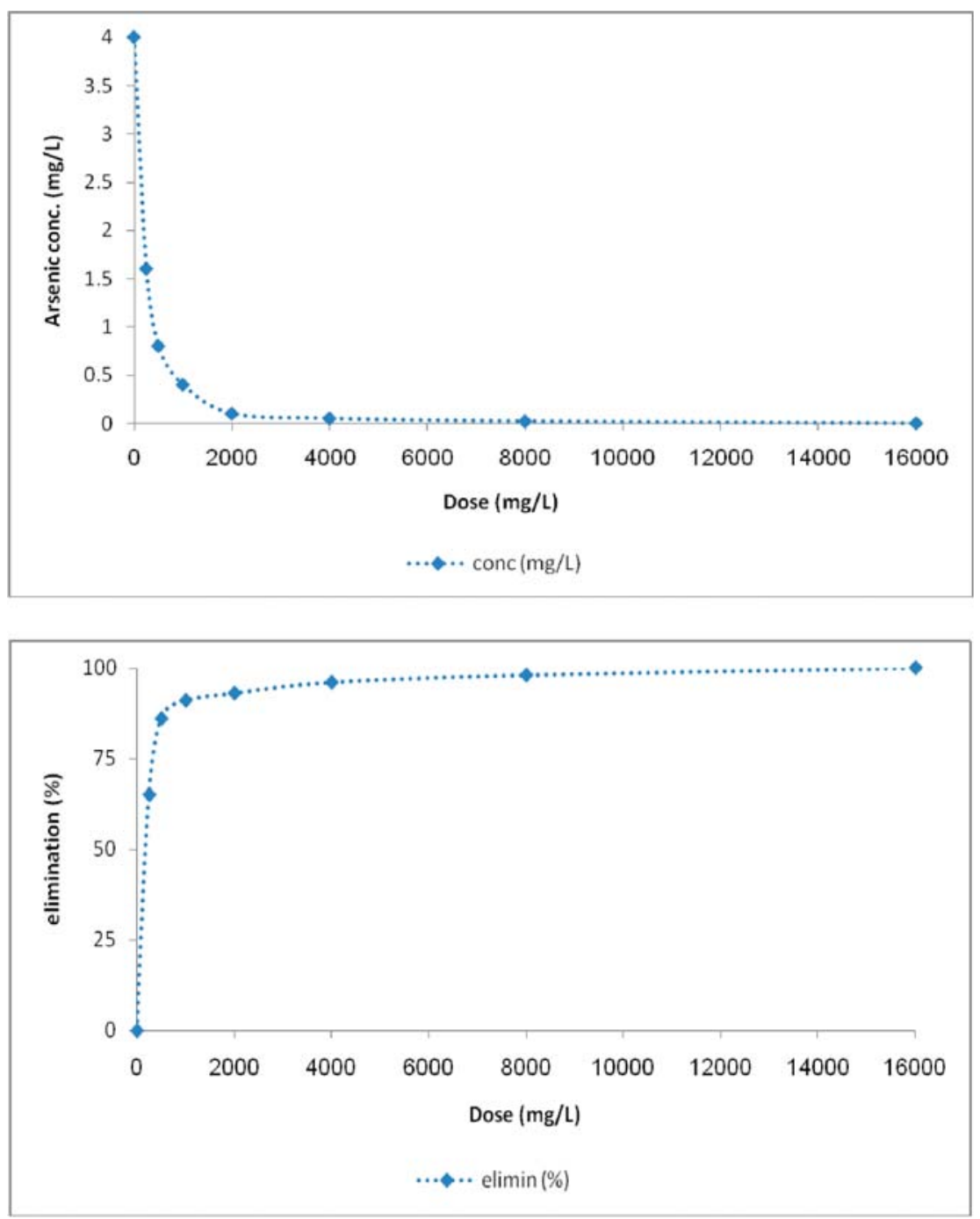

Figure 5: As (V) adsorption using activated alumina; arsenic's initial concentration is $4 \mathrm{mg} / \mathrm{L}$; experience time 24 hours [16].

column capacity based on the $\mathrm{pH} 6.0$ operation with a source water containing $0.1 \mathrm{mg} / \mathrm{L}$ As (V) to be $1400 \mathrm{~g}$ As $(\mathrm{V}) / \mathrm{m}^{3}$ of alumina.

None of the results from analysis of spent activated alumina from this Plant indicate exceedances of TCLP limits.

\subsection{Lime softening}

The softening by lime method is normally used for decreasing the water hardness. The water hardness is the result of calcium and magnesium ions content of water, which are removed through the relevant process in the form of $\mathrm{CaCO}_{3}$ and $\mathrm{Mg}(\mathrm{OH})_{2}$ precipitates. 

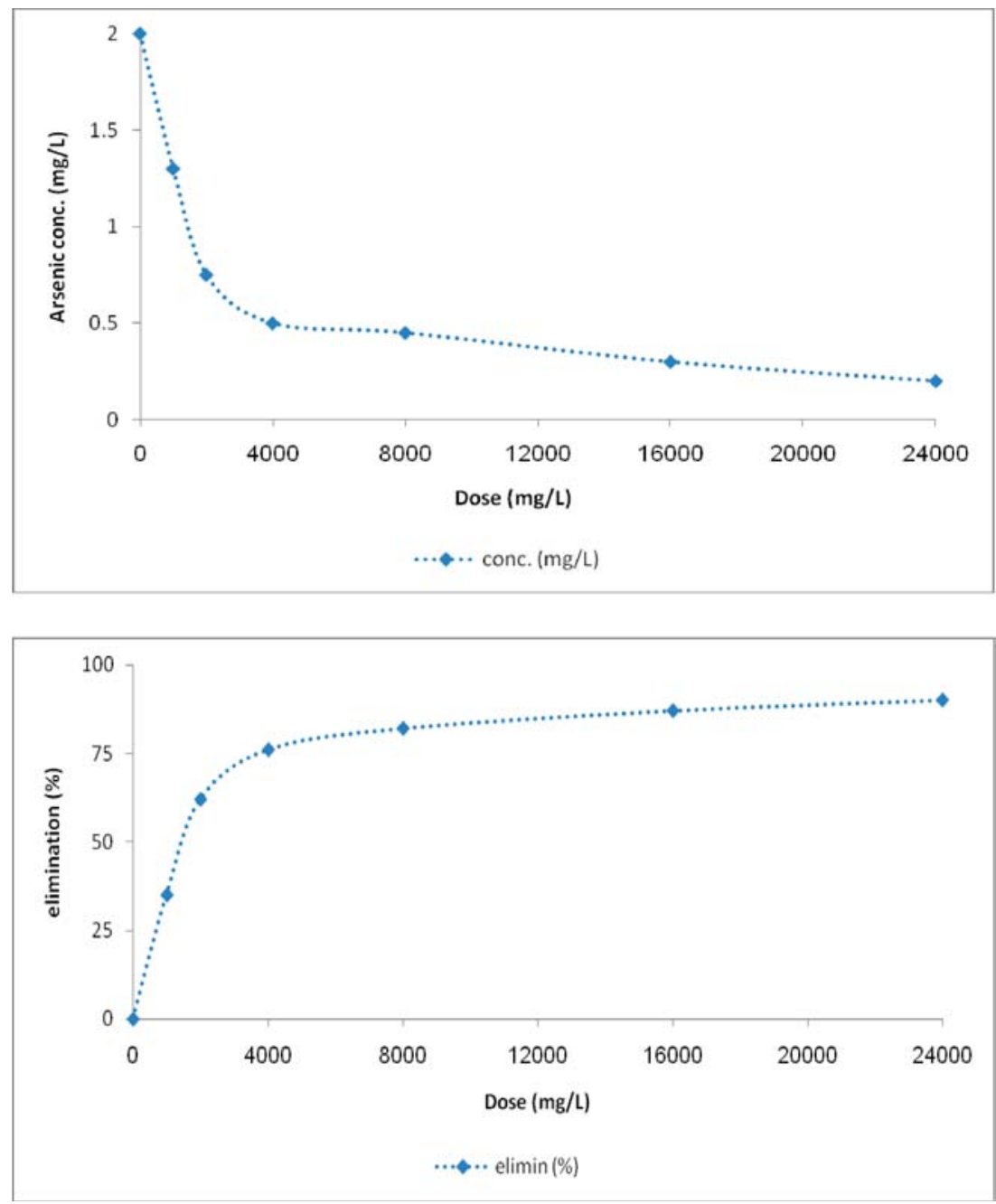

Figure 6: As (III) adsorption using activated alumina; arsenic's initial concentration is $2 \mathrm{mg} / \mathrm{L}$; experience time 24 hours [20].

For softening process, the lime must be used separately or combined with soda; it depends on the type of hardness. The lime should be used by low hardness or carbonate hardness; in case that the hardness is caused by a non-carbonate material, the lime or lime with soda must be used. Sometimes, the caustic soda is also used instead of lime or lime and soda to decrease produced sludge $[9,18]$. Table 2 shows the analytical results of pilot operation.

Lime softening operated within the optimum $\mathrm{pH}$ range of more than 10.5 is likely to provide a high percentage of arsenic removal (about 90\%) for influent concentrations of up to $0.05 \mathrm{mg} / \mathrm{L}$. It may be difficult to reduce consistently to $0.01 \mathrm{mg} / \mathrm{L}$ by lime sof- 
Table 2: Analytical results [18].

\begin{tabular}{lccrcc}
\hline Row & Sample code & $\begin{array}{c}\text { Total hardness } \\
(\mathrm{mg} / \mathrm{L} \text { as } \\
\left.\mathrm{CaCo}_{3}\right)\end{array}$ & $\mathrm{pH}$ & $\begin{array}{c}\text { Arsenic } \\
\text { concentration } \\
(\mathrm{mg} / \mathrm{L})\end{array}$ & $\begin{array}{c}\text { Arsenic } \\
\text { removal (\%) }\end{array}$ \\
\hline 1 & A-1-1 & 247 & 4.47 & 0.041 & - \\
2 & $\mathrm{~A}-3-1$ & 145 & 10.31 & 0.017 & 58.8 \\
3 & $\mathrm{~A}-3-2$ & 151 & 10.55 & 0.016 & 61.1 \\
4 & $\mathrm{~A}-3-3$ & 137 & 11.12 & 0.006 & 87.0 \\
5 & $\mathrm{~B}-1-1$ & 230 & 7.36 & 0.097 & - \\
6 & $\mathrm{~B}-3-1$ & 154 & 8.97 & 0.073 & 25.6 \\
7 & $\mathrm{~B}-3-2$ & 143 & 9.62 & 0.060 & 38.8 \\
8 & $\mathrm{~B}-3-3$ & 121 & 10.94 & 0.020 & 79.7 \\
9 & $\mathrm{C}-1-1$ & 251 & 7.63 & 0.146 & - \\
10 & $\mathrm{C}-3-1$ & 170 & 9.59 & 0.095 & 35.4 \\
11 & $\mathrm{C}-3-2$ & 153 & 10.02 & 0.089 & 39.6 \\
12 & $\mathrm{C}-3-3$ & 124 & 10.87 & 0.017 & 88.5 \\
13 & $\mathrm{D}-1-1$ & 244 & 7.19 & 0.210 & - \\
14 & $\mathrm{D}-3-1$ & 167 & 9.33 & 0.140 & 33.4 \\
15 & $\mathrm{D}-3-2$ & 152 & 9.86 & 0.136 & 35.1 \\
16 & $\mathrm{D}-3-3$ & 134 & 11.07 & 0.037 & 82.3 \\
\hline
\end{tabular}

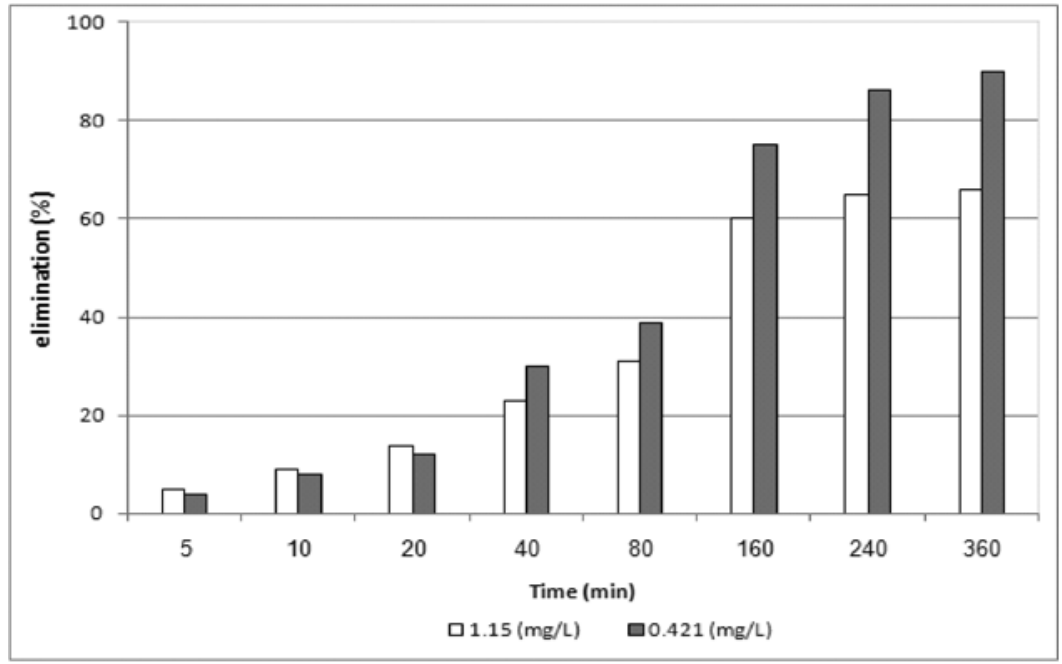

Figure 7: Higher concentration arsenic removal using $500 \mathrm{mg} / \mathrm{L}$ activated alumina; pH 5.8 [16]. 

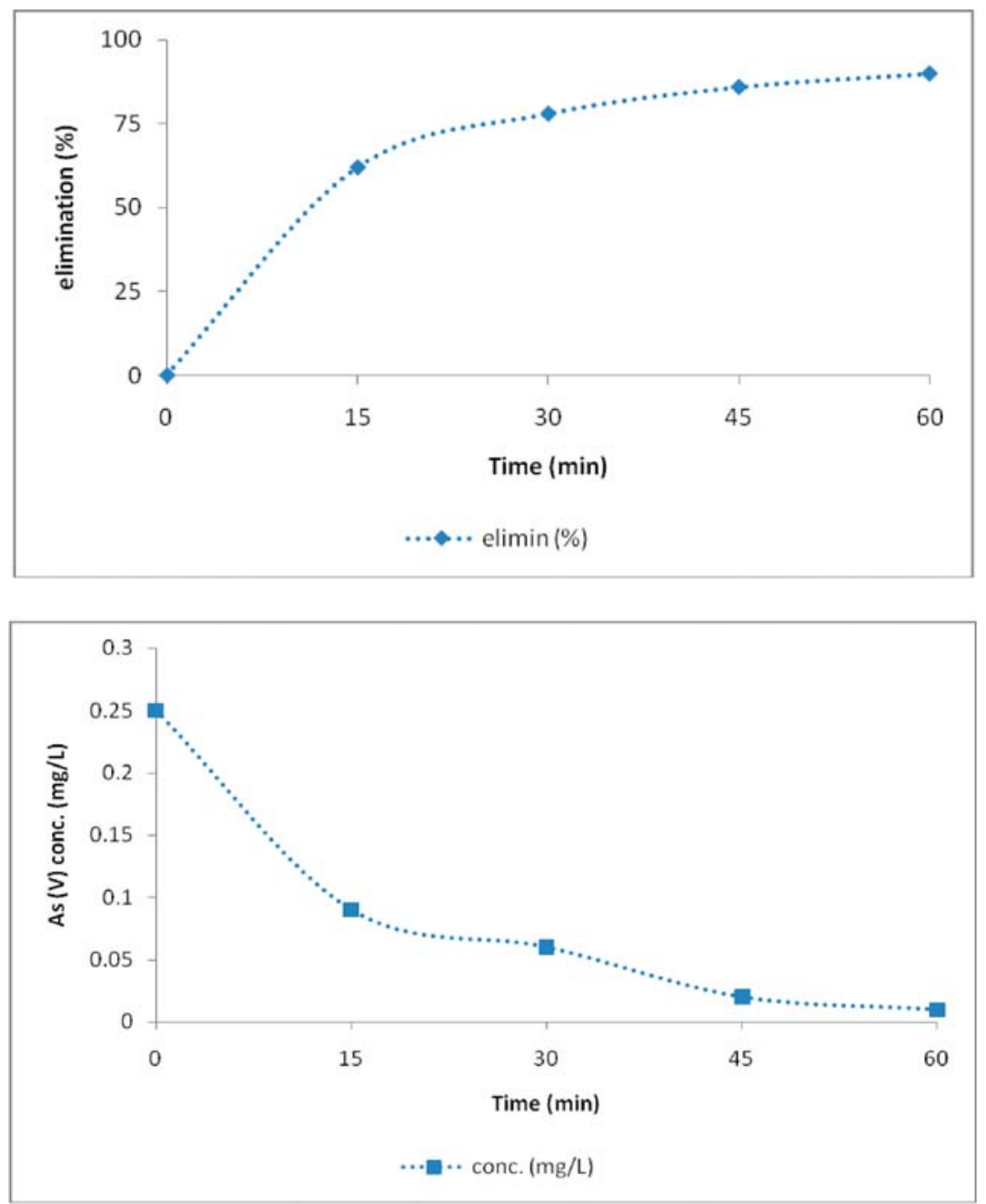

Figure 8: Influence of adsorption time on As (V) removal using activated alumina; arsenic's initial concentration is $0.25 \mathrm{mg} / \mathrm{L}$; alumina concentration $2000 \mathrm{mg} / \mathrm{L}$ [16].

tening alone. Systems using lime softening may require secondary treatment to meet that goal.

\section{CONCLUSIONS}

Exposure to arsenic contaminated drinking water is a major threat to human health. Millions of people across the world are exposed to arsenic contaminated drinking water with concentrations far in excess of the $0.01 \mathrm{mg} / \mathrm{L}$ maximum permissible level established by the World Health Organization. Two different arsenic removal process categories were investigated in this paper. According to the results of three operated activated alumina pilot plants, we can conclude that this media could have application as a safe adsorbent for removal of arsenic 

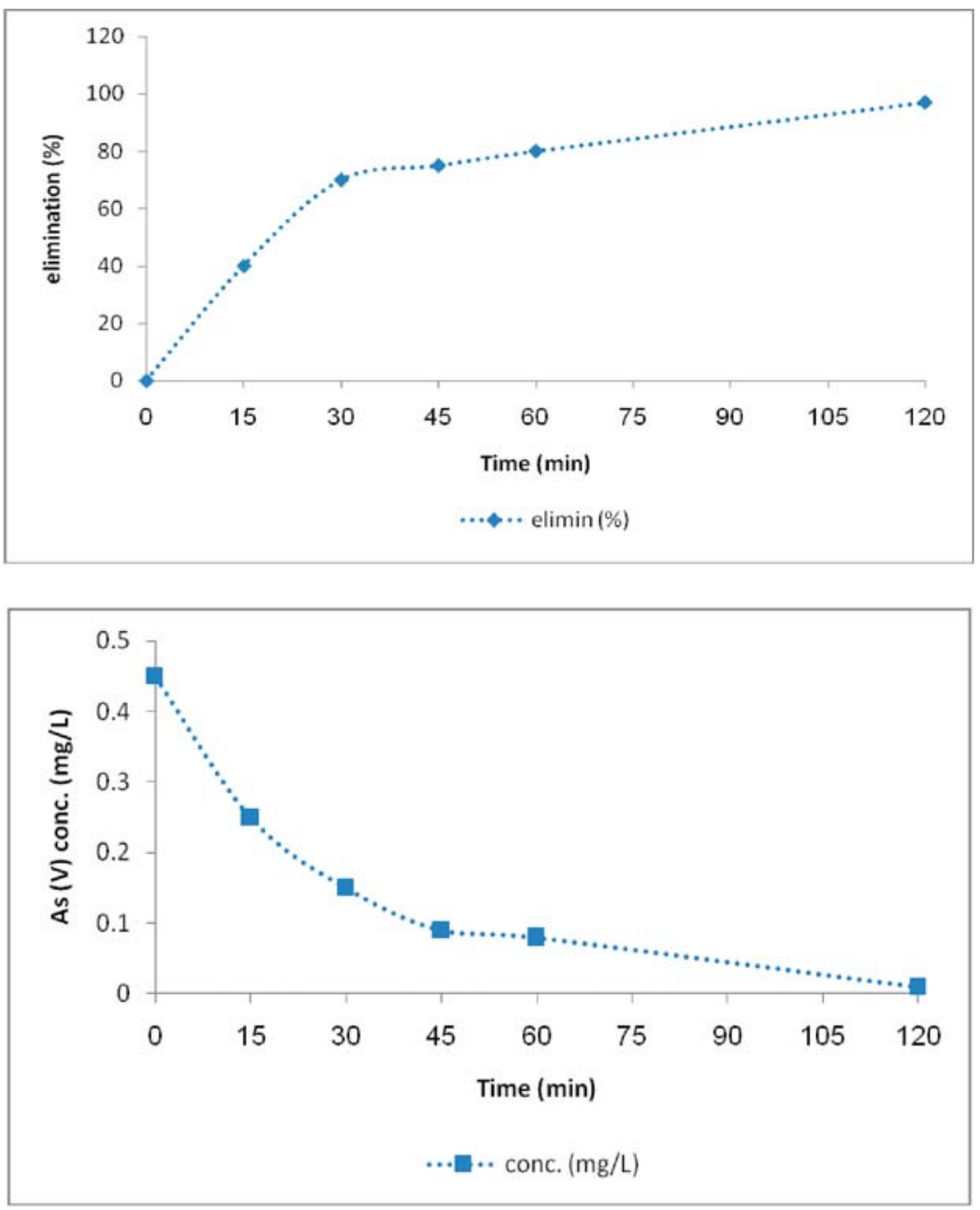

Figure 9: Influence of adsorption time on As (V) removal using activated alumina; arsenic's initial concentration is $0.445 \mathrm{mg} / \mathrm{L}$; alumina concentration $2000 \mathrm{mg} / \mathrm{L}$; pH 5.8 [16].

from drinking water in treatment systems in form of adsorptive column. Experiments using different concentrations of arsenic showed that adsorption of arsenic on activated alumina are a first order reaction; rate of reaction is dependent on initial concentration of arsenic. Arsenite should be oxidized to arsenate before activated alumina treatment. None of the results from analysis of spent activated alumina from operated plants indicate exceedances of TCLP limits. The SEM analysis of the virgin modified activated alumina and the exhausted media grains didn't show any change in the structural morphology of the media. Arsenite removal capacity is much less than for arsenate (more than 90\%). Activated alumina is relatively well known and commercially available but needs replacement after four or five regenerations.

Lime softening is proven effective in laboratories and at pilot scale and its efficiency should be largely independent of scale. Disadvantages include extreme pH more than 10.5 and large volume of waste generated. It is inexpensive, but more expensive than coagulation 

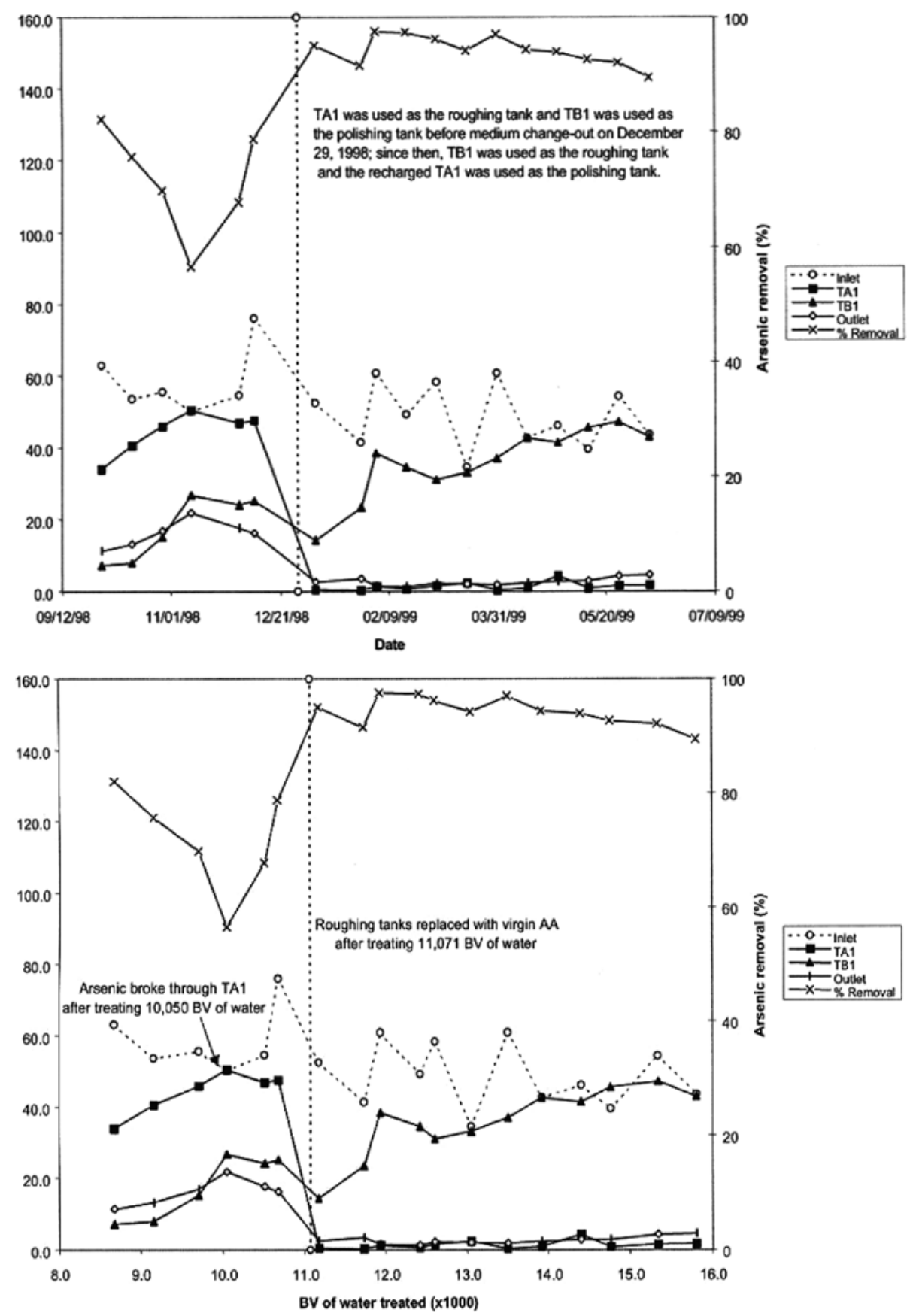

Figure 10: Total arsenic analytical results during long-term sampling [17]. 
with iron salts or alum because of larger doses required, and wastes handling. The chemicals are available commercially but readjustment of $\mathrm{pH}$ is required. Removal efficiency for arsenic (III) is 30-60\% and for arsenic (V) it is more than $90 \%$.

\section{ACKNOWLEDGMENTS}

Financial support was provided by the National Water and Wastewater Company (NWWC) and Iranian National Management and Planning Organization. Special thanks to water and wastewater authority of province Kurdistan and Faculty of Public Health Tehran University of Medical Sciences.

\section{REFERENCES}

[1] Kurdistan Province Rural Water and Wastewater, Report, 2005.

[2] Haque, A.A.M., Thwe, H.M., Jayasuriya, H.P.W., Hossain, H.Z., Rahman, M., Harunur-Rashid, M. \& Matsumura, K., Groundwater arsenic contamination: food safety and human health hazards in Bangladesh. Chiang Mai University Journal of Natural Science, 6(2), pp. 321-339. 2007.

[3] World Health Organization (WHO), Arsenic in drinking water, www.who.int/mediacenter/factsheets/fs210/en/index.html. 2010.

[4] World Health Organization, (1996, 1999, 2001), Guidelines for Drinking Water Quality, Arsenic and Arsenic Compounds, Arsenic in Drinking Water, Geneva.

[5] Mohan, D., Pittman Jr., C.U., Arsenic removal from water/wastewater using adsorbents, a critical review, Elsevier, 1-42. 2007.

[6] US Environmental Protection Agency (EPA), (1998, 1999, 2000, 2001), Research Plan for Arsenic in Drinking Water - Treatment, Technologies and Costs for Removal of Arsenic from Drinking Water, National Primary Drinking Water Regulation, Office of Ground Water \& Drinking Water.

[7] Smedley, P.L., Kinniburg, D.G., A review of the source, behavior and distribution of arsenic in natural waters, Applied Geochemistry 17, pp. 517-568. 2002.

[8] Idswater, ActiGuard AAFS50 Activated Alumina for the Removal of Arsenic from Potable Water, www.idswater.com/water/us/activated_alumina/457/products.html. 2010.

[9] Reynolds, T.D., Richards, P.E., Operational and Process Units in Environmental Engineering. PWS Publishing Company, Boston, London, 2000.

[10] Jain, C.K, Ali, I., Arsenic: Occurrence, Toxity and Speciation Techniques. ater Research 34 (17), pp. 4304-4312. 2000.

[11] Badalians Gholikandi, G., Water Chemistry, 2nd edition, Publ. Nopardazan, Tehran, Iran, 2006.

[12] Vu, K.B., Kaminski, M.D., Nunez, L., Review of Arsenic Removal Technologies for Contaminated Groundwaters, ANL-CMT-03/2, Argonne National Laboratory, Illinois 60439,University of Chicago, USA. 2003.

[13] Johnston, R., Heijnen, H., Safe Water Technology for Arsenic Removal, citeseerx.ist. psu.edu/.../arsenic/.../Mohan_As_removal_adsorbents.pdf. 2002.

[14] Ravenscroft, P, Homepage, Documents. www.rgs.org/.../Arsenic+the+geography+of+a +global+problem.htm, 2010.

[15] Reynolds, T.D., Richards, P.E. (2000), Operational and Process Units in Environmental Engineering, Boston, London: PWS Pub. Co.

[16] Mosaferi, M., Mesdaghinia, A.R., Removal of Arsenic from Drinking Water Using Modified Activated Alumina, Iranian Water and Wastewater Journal, No. 55, Esfahan, Iran. 2005. 
[17] Wang, L., Chen, A., Fields, K., Arsenic Removal from Drinking Water by Ion Exchange and Activated Alumina Plants, USEPA/600/R-00/088, Cincinnati, USA. 2000.

[18] Badalians Gholikandi, G., Abbaspour, R., Technical and Financial Analysis of Groundwater Remediation System, Chemical Contaminants Treatment, national research program, PWUT, Tehran, 2006.

[19] APHA., Standard Methods for the Examination of water and wastewater. American Public Health Association: Washington, D. C. 2005.

[20] Badalians Gholikandi, G., Sadrzadeh Ardebili, M., Riahi, R., Orumieh, HR., Arsenic Polluted Groundwater: Epidemiological Study and Efficient Removal Method, Environmental Health Risk V, Proceeding book, WIT, UK, pp. 133-142, 2009.

[21] Clifford, D., Lin, C.C. (1991), Arsenic III and Arsenic V Removal from Drinking Water in San Ysidro, New Mexico, USEPA/600/2-91/011, Cincinnati, USA.

[22] Clifford, D., Ion Exchange and Inorganic Adsorption. In American Water Works Association (AWWA)(Eds.),Water Quality and Treatment: A Handbook of Community Water Supplies. 5th ed., NY, McGraw-Hill. 1999.

[23] Clifford, D., Rosenblum, E., The Equilibrium Arsenic Capacity of Activated Alumina, USEPA CR-807939-02, Cincinnati, USA. 1982.

[24] Fox, K., Field Experience with Point-of-Use Treatment Systems for Arsenic Removal, J. AWWA, pp.94-101. 1989.

[25] UStoday Arsenic in drinking water seen as threat, http://www.ustoday.com/news/ world/2007-08-30-553404631_x.htm, 2007. 